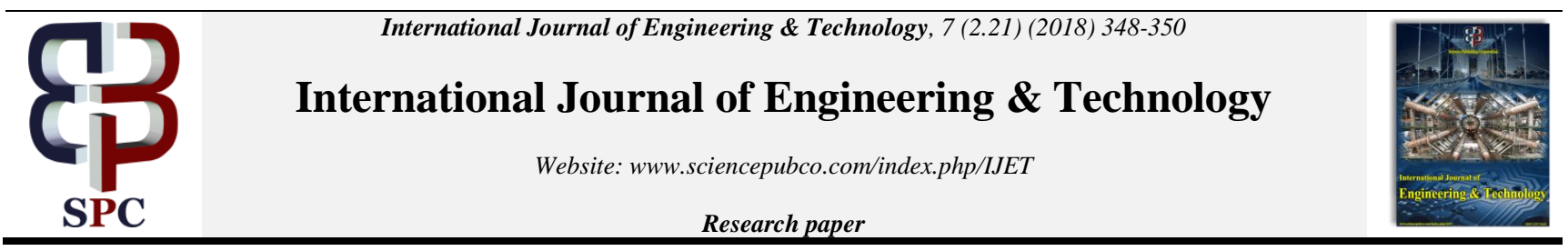

\title{
Fire fighting robot with vision camera and gas sensors
}

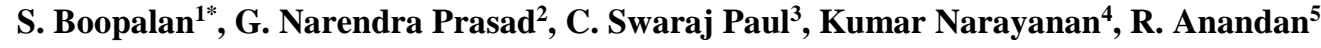 \\ ${ }^{I}$ Department of Computer Science \& Engineering, Vels Institute of Science, Technology \& Advanced Studies(VISTAS), Chennai, India. \\ ${ }^{2}$ Department of Computer Science \& Engineering, Vels Institute of Science, Technology \& Advanced Studies(VISTAS), Chennai, India. \\ ${ }^{3}$ Department of Computer Science \& Engineering, Vels Institute of Science, Technology \& Advanced Studies(VISTAS), Chennai, India \\ ${ }^{4}$ Department of Computer Science \& Engineering, Vels Institute of Science, Technology \& Advanced Studies(VISTAS), Chennai, India. \\ ${ }^{5}$ Department of Computer Science \& Engineering, Vels Institute of Science, Technology \& Advanced Studies(VISTAS), Chennai, India. \\ *Corresponding author E-mail:sgbpalan97@gmail.com
}

\begin{abstract}
Yearly there are 150+ deaths are occurring due to fire fighting operations. Most of the deaths are due to presence of poisonous gases being present in the fire fighting areas. If we able to inform fire fighter worker about the presence of gases and hazardous situation, we can able to save their lives. In now-a-days robots play a vital part in industry and normal life of human beings, robots are the assemble of different parts or things which are made by human in order to complete any work with more accuracy. "Fire Fighting Robot with gas sensors". The design is costless and will do lot of work. It can be used in industry and for domestic purpose. Important parts involved in the construction of robot are gas sensors, water tank, wireless remote and wireless android device Wi-Fi enabled Camera, A wireless robot will do effective work, thereby making it possible to control the robot from remote location. Keeping all above factors in mind the Robot is capable of being remotely controlled and live video buffering i.e. possessing a multimedia interface was convinced and developed.
\end{abstract}

Keywords: Arduino IDE, raspbian Jessie lite OS, python IDLE, fire Robot, carbon dioxide sensor, carbon monoxide sensor

\section{Introduction}

Fire Fighters are being exposed to various hazardous situations. In most of the situations they may not know exact scenario of their working place. The protective equipment can protect them up to a certain extent. Safety in fire fighting areas requires continuous attention of parameters such as temperature and some noxious gases such as $\mathrm{CO}, \mathrm{CO} 2, \mathrm{CH} 4, \mathrm{LPG}$ and Smoke.

There's a life of unique systems or schemes which are put into region for the ones risky environments with a purpose to guard the worker from harm. The better degree term for those systems/schemes is the Occupational health and safety. the global corporation of Standardization or ISO have a elegant specifically the ISO 45001. This famous dreams to lessen the legal responsibility of occupational injuries and sicknesses now not only to benefit the human beings however additionally the economic machine upon which this work build.As the situation is hazardous monitoring the data near from the operating location is putting life at risk. The proposed design WSN based Life Save System gives a complete replica of situation in a hazardous place. Without nearing the place, Scavengers and Fire Fighters can know about the hazardous situation by using the proposed system. They can arrange protective equipment, corrective measures accordingly.

\section{Related works}

\section{Automatic fire fighting robot}

To make an automatic fireplace Extinguisher robotic which could come across and extinguish a hearth on its personal is assembling of various components. A Thermostat Sensor, sometimes called an optical sensor, Detects visually sense the fire, usually in a narrow range, in order feature in forest operations, at industrial check points in undeveloped villages, to momentarily distract an fire, to helpful fire covered area at much less time and useful from dangerous hazardous the environment using fire extinguisher robot. A dazzler, occasionally called an optical distracter, transmits a visually excessive light, typically in a slender beam, if you want to attract the attention of someone and to make them alert to heck points in non-fight land operations, to momentarily distract an assailant, to alert drivers in automobiles coming near a take a look at factor, and to alert civilian visitors to approaching forces. Designing a fire fighting robot vary from a simple and cheap to difficult and cost expensive. The choice of which type of navigation scheme is to be employed depends truly on the requirements of the character. From industrial factor of view those automated fire preventing robots are employed as items company to prevent the fire and paintings as the hearth extinguisher a few different wherein manpower isn't always viable to be reached. A simple Automatic Fire Fighting robots sense the fire using simple Thermostat sensors but when it is on out of sense range it have to make a proper range for sensing the fire. 


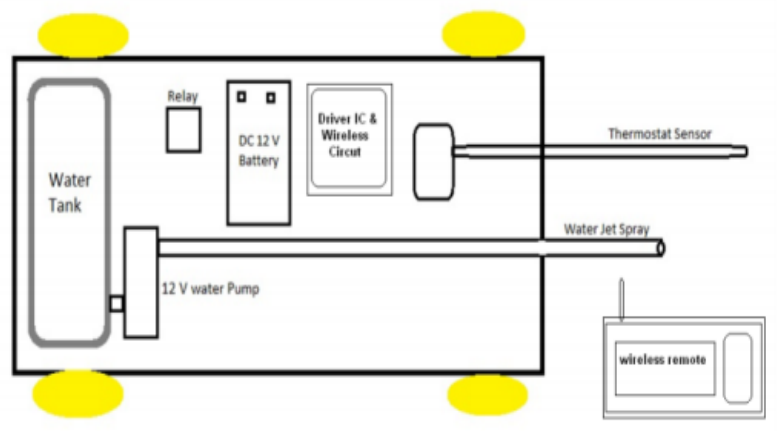

Fig. 1: Automatic fire fighting robot architecture

\section{Design of wireless sensor network (WSN) based life save system for scavenging \& fire fighting operations effect of noxic gases on human body}

Carbon Monoxide (CO), is often referred to as the-Silent Killer| due to its capability to take lives quickly and quietly while its victims never even knew they had been at hazard. it's far in detectable to humans, being both tasteless and odourless, and in high sufficient concentrations it could kill inside minutes.

Table 1: Effect of Carbon Monoxide on Human Body

\begin{tabular}{|l|l|}
\hline Level of CO & Health Effects, and Other Information \\
\hline 0 PPM & Ambient Air. \\
\hline 9 PPM & Safe limit for indoor level \\
\hline 200 PPM & Head ache and fatigue. \\
\hline 1600 PPM & $\begin{array}{l}\text { Nausea, Loss of Consciousness, long time exposure may lead } \\
\text { death }\end{array}$ \\
\hline 12,800 PPM & Death within minutes. \\
\hline
\end{tabular}

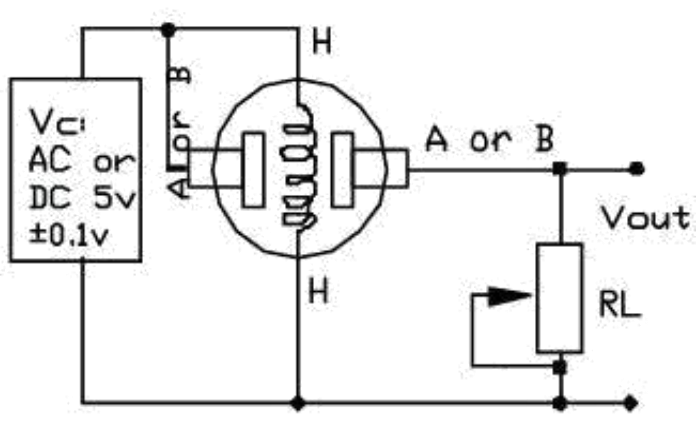

Fig. 2: MQ 7 sensor

\section{Effect of carbon dioxide $\mathrm{CO} 2$}

$\mathrm{CO} 2$ is a clearly happening atmospheric fuel this is considered safe at degrees below 0.five\% consistent with OSHA standards. however, occupational hazards related to $\mathrm{CO} 2$ exposure may additionally occur under positive situations. the yankee Society of Heating, Refrigerating, and air conditioning Engineer, Inc., recommends that indoor air $\mathrm{CO} 2$ degrees be less than $700 \mathrm{ppm}$ above the out of doors air awareness of $\mathrm{CO} 2$.

Table 2: Effect of Carbon Dioxide on Human Body

\begin{tabular}{|l|l|}
\hline Level of CO2 & Health Effects, and Other Information \\
\hline $250-350$ PPM & Normal background concentration in outdoor ambient air \\
\hline 9 PPM & $\begin{array}{l}\text { Concentration typical of occupied indoor spaces with good air } \\
\text { exchange }\end{array}$ \\
\hline $2,000-5,000$ & Headaches, sleepiness and stagnant, stale, stuffy air. Poor \\
PPM & concentration, loss of attention, increased heart rate. \\
\hline$>40,000 \mathrm{PPM}$ & $\begin{array}{l}\text { Exposure may lead to serious oxygen deprivation resulting in } \\
\text { permanent brain damage, coma, even death. }\end{array}$ \\
\hline
\end{tabular}

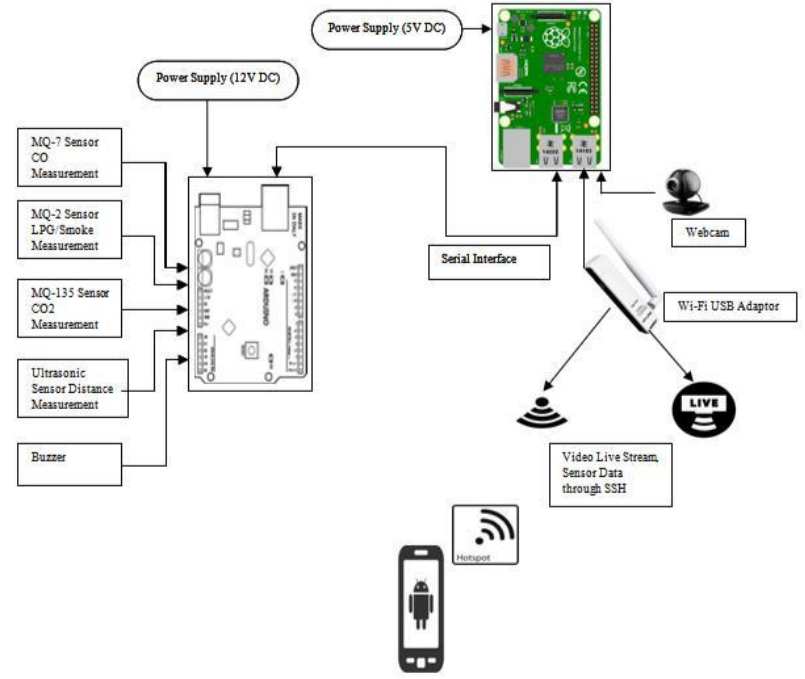

Fig. 3: System overview

\section{Fire fighting robot with vision camera and gas sensors}

The design uses Raspberry $\mathrm{Pi} \mathrm{B}+$, it is a mini computer. The Raspberry Pi booted with Raspbian Jessie Lite Operating System. Raspberry Pi having 512 MB RAM, 4 USB Ports, 40 GPIO pins, Video out pin, 3.5mm Audio jack, SoC Broadcom 2835 and supports Wi-Fi through USB Wi-Fi adaptor, LAN through Ethernet Socket.

\section{Wi-Fi network}

The design uses Mobile Wi-Fi hotspot to set a portable Wi-Fi Network 802.11u IEEE standard. The Wi-Fi hotspot is secured with Wi-Fi Protected Access -Pre Shared Key (WPA-PSK) client authentication method. The Wi-Fi network Service Set Identified (SSID), Network Security Key is configured with Raspberry Pi $\mathrm{B}+$ module.

\section{Live stream network}

The video is recorded using Webcam, the webcam communicates to Raspberry Pi B+ using USB Cable. The resolution of the webcam can be fixed up to $6048 * 4032$ and maximum frame rate 30fps. The video is recorded using webcam. The webcam communicates Raspberry $\mathrm{Pi} \mathrm{B}+$ using USB Communication protocol. The video is live video is streamed on the network by using Real time Streaming Protocol (RTSP), Real time Transport Control Protocol (RTCP).

Open source software package called _Motion' is installed in Raspberry $\mathrm{Pi} \mathrm{B}+$. The motion software is configured to broadcast the live stream through the Raspberry Pi B+ (local host) IP Address on the network and it is configured for video for video codec, frame rate, port and resolution etc.

The design uses video codec-mpeg4, port-8081, framesrate$100 \mathrm{fps}$, resolution $640 * 480$. The live stream can be stopped or started from the terminal using SSH-Client on the network. The live video stream can be viewed by any device on the network by accessing IP address of Raspberry Pi B+.

\section{Sensor data logging and monitoring}

The data from sensors are logged to Arduino Uno. The sensor data is communicated serially to Raspberry $\mathrm{Pi} \mathrm{B}+$ using USB serial cable. The Raspberry $\mathrm{Pi} \mathrm{B}+$ is configured to run a python program, which get the serial data and displays it on terminal and it writes the same to a specified text file. The text file can be viewed through terminal. Users who are on the same network can 
login through SSH can view the data by accessing the text file or terminal.

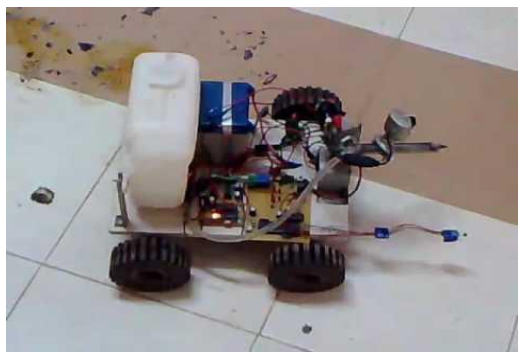

\section{Performance comparison of automatic fire fighting robot with fire fighting robot with vision camera and gas sensors}

1. The existing robot i.e automatic fire fighting robot cannot give information about the level of the harmful gases present in the fire accident zone but the fire fighting robot with vision camera and gas sensors gives the data about the level of harmful gases present there

2. The wireless sensor network based life saving system is being limited to poor communication system which is improved by using wi-fi device.

3. The design of wireless sensor network (WSN) based life save system for scavenging \& fire fighting operations is non moveable but fire fighting robot with vision camera and gas sensors is move able and get the accurate data.

Table 3: Output under Room Environment

\begin{tabular}{|l|l|l|}
\hline Parameter & Expected Outcome Level & Actual Outcome Level \\
\hline $\mathrm{CO}$ & $0 \mathrm{ppm}$ & $0 \mathrm{ppm}$ \\
\hline $\mathrm{CO} 2$ & $350-450 \mathrm{ppm}$ & $262 \mathrm{ppm}$ \\
\hline Smoke & $0 \mathrm{ppm}$ & $0 \mathrm{ppm}$ \\
\hline
\end{tabular}

The output of room environment should be within the following values given in the below table

Table 4: Output under Smoke Environment

\begin{tabular}{|l|l|l|}
\hline Parameter & Expected Outcome Level & Actual Outcome Level \\
\hline $\mathrm{CO}$ & $2-3 \mathrm{ppm}$ & $2 \mathrm{ppm}$ \\
\hline $\mathrm{CO} 2$ & $450-600 \mathrm{ppm}$ & $372 \mathrm{ppm}$ \\
\hline Smoke & $5-7 \mathrm{ppm}$ & $5.83 \mathrm{ppm}$ \\
\hline
\end{tabular}

Approximate values are used in expected outcome. The system proves $80 \%, 71 \%, 95 \%$ (approx.) accuracy to gases $\mathrm{CO}, \mathrm{CO} 2 \&$ Smoke. The system over all accuracy $82 \%$ (approx.)

\section{Conclusion}

Therefore, WSN based Life Save System was designed. The system is compact and can be fixed to any drone or mobile robot to monitor CO, CO2 gases and LPG, Smoke levels. The system will communicate data from sensor node and stream live video to user's mobile through Wi-Fi. The system will give exact scenario through the sensor data and video live stream. The can also be implemented in Mining and Chemical Industries for monitoring hazardous zone

\section{References}

[1] Tiwari G, "Hardware/Software Based a Smart Sensor Interface Device for Water Quality Monitoring in IoT Environment", International Journal of Technology and Science, Vol.3, No.1, (2011), pp.5-9.

[2] Henriques V \& Malekian R, "Mine safety system using wireless sensor network", IEEE Access, Vol.4, (2016), pp.3511-3521.

[3] Carbon Mono Oxide Health Issues, CarbonMonoOxide.com

[4] U.S Department of the Interior Buraue of Land Management NEPA (National Environment Policy Act)
[5] U.S Department of Health and Human Services- National Institute of Occupational Safety and Health Occupational Health Guidance for LPG, 2017.

https://www.cdc.gov/niosh/docs/81-123/pdfs/0372.pdf.

[6] New York State Govt. Department of Health- Exposure to Smoke from Fires, 2017. https://www.health.ny.gov/environmental/outdoors/air/s

[7] Jiru P, "Design of Intelligent Monitoring System", Third International Conference on Instrumentation, Measurement, Computer, Communication and Control, (2013), pp.407-410.

[8] Davide Gironi, Design of cheap CO2 Monitor Using MQ135 Sensor Using AVR ATMega, (2014).

[9] Sandbox Electronics MQ-2 Smoke/LPG/CO Gas Sensor Module, Product Datasheet, (2014).

[10] Flores KO, Butaslac IM, Gonzales JEM, Dumlao SMG \& Reyes, RS, "Precision agriculture monitoring system using wireless sensor network and Raspberry Pi local server", Region 10 Conference (TENCON), (2016), pp.3018-3021.

[11] Oza N \& Gohil NB, "Implementation of Cloud Based Live Streaming for Surveillance", International Conference on Communication and Signal Processing, (2016).

[12] Li XQ, Ding X, Zhang Y, Sun ZP \& Zhao HW, "IoT family robot based on raspberry Pi", International Conference on Information System and Artificial Intelligence (ISAI), (2016), pp.622-625.

[13] Olimex Ltd,MQ-2 Semiconductor Sensor for Combustible GasData Sheet.

[14] Olimex Ltd,MQ-135 Gas Sensor Technical Data Sheet.

[15] TP Link WN821N Wi-Fi Adaptor Specifications, Users Manual.

[16] Dohare YS, Maity T, Paul PS \& Prasad H, "Smart low power wireless sensor network for underground mine environment monitoring", 3rd International Conference on Recent Advances in Information Technology (RAIT), (2016), pp.112-116. 